\title{
Betametasona e extrato aquoso de Arctium lappa no tratamento da angiostrongilíase
}

\author{
Betamethasone and aqueous extract of Arctium lappa \\ for treating angiostrongyliasis
}

Camila Argenta Fante ${ }^{1}$, Solange Dieterish ${ }^{1}$ e Rubens Rodriguez ${ }^{2}$

\begin{abstract}
RESUMO
Angiostrongylus costaricensis é um parasita que causa angiostrongilíase abdominal em humanos, seu tratamento inclui o uso de antiinflamatórios apesar da falta de estudos que justifiquem esta conduta. 0 objetivo deste artigo é avaliar o efeito da betametasona e da Arctium lappa na evolução de lesões intestinais induzidas pelo parasita. Utilizou-se camundongos Swiss, machos, adultos, distribuídos em 4 grupos: infectados tratados com betametasona; com Arctium lappa; não tratados e grupo controle. Os tratamentos iniciaram no $15^{\circ}$ dia de infecção e permaneceram por 15 dias. Infiltrado eosinofílico e granuloma foram avaliados (1-leve; 2-moderado; 3-severo). A betametasona permitiu a evolução das lesões para formas mais graves, enquanto o extrato não interferiu na progressão da patologia. As substâncias empregadas não mostraram eficácia na proteção das lesões induzidas pelo Angiostrongylus costaricensis em camundongos. Estes achados desmotivam o uso de betametasona e Arctium lappa em humanos acometidos por angiostrongilíase abdominal.
\end{abstract}

Palavras-chaves: Angiostrongilíase. Antiinflamatórios. Betametasona. Arctium lappa.

\begin{abstract}
Angiostrongylus costaricensis is a parasite that causes abdominal angiostrongyliasis in humans. The treatment for it includes the use of antiinflammatory drugs, despite the lack of studies to justify this approach. The objective of this paper was to evaluate the effect of betamethasone and Arctium lappa on the evolution of intestinal lesions induced by this parasite. Adult male Swiss mice were used, distributed into four groups: infected and treated with betamethasone; infected and treated with Arctium lappa; infected and not treated; and control group. The treatments were started on the $15^{\text {th }}$ day after infection and continued for 15 days. The presence of eosinophilic infiltration and granuloma was evaluated (1-mild; 2-moderate; 3-severe). Betamethasone allowed the lesions to evolve into more severe forms, while the extract did not interfere with disease progression. The substances applied were ineffective for protection against the lesions induced by Angiostrongylus costaricensis in mice. These findings discourage the use of betamethasone and Arctium lappa for humans affected by abdominal angiostrongyliasis.
\end{abstract}

Key-words: Angiostrongyliasis. Anti-inflammatory drugs. Betamethasone. Arctium lappa.

O Angiostrongylus costaricensis é um parasita que habita os ramos da artéria mesentérica de roedores silvestres e pode infectar o homem produzindo uma doença conhecida por angiostrongilíase abdominal ${ }^{134}$.

Não existe tratamento específico capaz de erradicar 0 parasita. Normalmente, são usados fármacos antiinflamatórios para aliviar os sintomas ${ }^{12}$, apesar de não ter sido estabelecido até o momento, a eficácia desta conduta. 0 emprego de terapia antihelmíntica, por outro lado, não é recomendado por ineficácia em matar os vermes e em função da possibilidade de determinar migração errática dos vermes ${ }^{8}{ }^{10}$. Antiinflamatórios naturais, como o extrato aquoso de Arctium lappa, têm mostrado eficácia na inibição de processos inflamatórios agudos, agindo por meio da remoção de radicais livres ${ }^{2}$, redução de edema de pata induzido por carragenina ${ }^{7}$ e proteção de epitélio uretral após indução de infecção bacteriana, em ratos ${ }^{5}$. Por esta razão, os antiinflamatórios fitoterápicos podem ser de utilidade nesta patologia.

0 presente trabalho tem como objetivo avaliar a evolução das lesões de parede intestinal induzida pelo Angiostrongylus costaricensis, em camundongos, empregando-se fármaco antiinflamatório potente, betametasona, e extrato aquoso de Arctium lappa, planta medicinal comum no sul do Brasil com potencial propriedade antiinflamatória.

\footnotetext{
1. Setor de Farmacologia, Instituto de Ciências Biológicas, Universidade de Passo Fundo, Passo Fundo, RS. 2. Faculdade de Medicina, Universidade de Passo Fundo, Passo Fundo, RS.

Endereço para correspondência: Dra. Camila Argenta Fante. Rua Leopoldo Vilanova 31, 99070-180 Passo Fundo, RS.

Tel: $55543315-3741 / 55358836-6203$.

e-mail: camilafante@yahoo.com.br

Recebido para publicação em 21/01/2008

Aceito em 12/11/2008
} 


\section{MATERIAL E MÉTODOS}

Este estudo foi desenvolvido no decorrer do ano de 2005, no Biotério da Universidade de Passo Fundo (UPF) e no Instituto de Patologia de Passo Fundo. 0 estudo foi aprovado pelo Comitê de Ética em Pesquisa da Universidade de Passo Fundo.

Animais. Camundongos Swiss adultos, machos, pesando $40 \mathrm{~g}( \pm 5 \mathrm{~g})$, foram mantidos em grupos de 5 animais por gaiola e receberam água e ração à vontade. Antes e durante o período experimental, os animais foram colocados na mesma sala, para ambientação.

Material vegetal e fármacos. Raízes de Arctium lappa foram obtidas de uma propriedade agrícola próxima à Universidade de Passo Fundo, que não faz uso de agrotóxicos. Um exemplar está depositado no herbário da Universidade de Passo Fundo sob o número 9.225. 0 material vegetal foi secado em estufa de ar circulante sob temperatura não superior a $40^{\circ} \mathrm{C}$ por 7 dias. Os extratos foram obtidos por decocção, utilizando-se uma relação droga:solvente 1:10 (m/v). 0 líquido extrator utilizado foi água. Após filtração e arrefecimento, o extrato foi levado à secura em evaporador rotatório. Como fármaco antiinflamatório convencional, foi utilizada a betametasona (Celestone ${ }^{\circledR}$, ScheringPlough, Rio de Janeiro, Brasil).

Modelo investigacional. No início do estudo, através de sonda gástrica, 30 animais foram infectados com 10 larvas L3 de Angiostrongylus costaricensis. Estes animais foram distribuídos em três grupos, sendo dois grupos-teste (betametasona e Arctium lappa) e um grupo controle positivo. Dez animais não infectados serviram de grupo controle negativo. Os grupos ficaram assim distribuídos: $\mathrm{G}_{\mathrm{I}}$ - tratados com betametasona $3 \mathrm{mg} / \mathrm{kg}^{6}$; GII - tratados com extrato de Arctium lappa $500 \mathrm{mg} / \mathrm{kg}$; $\mathrm{G}_{\mathrm{III}}$ - animais inoculados com larvas L3 do Angiostrongylus costaricensis, não tratados; $\mathrm{G}_{\mathrm{IV}}$ - animais não inoculados.

0 tratamento foi iniciado a partir do $15^{\circ}$ dia após a inoculaçãao das larvas L3, período de aparecimento das lesões. As substâncias previstas foram administradas uma vez ao dia até o $39^{\circ}$ dia de estudo. Os animais que não morreram espontaneamente após o início dos tratamentos foram sacrificados no $40^{\circ} \mathrm{dia}$, com tiopental sódico, administrado por via intraperitoneal, na dose de $100 \mathrm{mg} / \mathrm{kg}$. Os intestinos delgado e grosso, o fígado, o coração, os pulmões, o estômago, os rins e o baço foram removidos, fixados em solução formalina a $10 \%$ por 24 horas e incluídos em bloco de parafina. Cortes histológicos foram obtidos de todos os órgãos retirados, cujas lâminas foram coradas com HE (hematoxilina-eosina).

Calibragem e cegamento dos pesquisadores. Dois pesquisadores padronizaram a forma de avaliação histológica do infiltrado eosinofílico e dos granulomas, determinando local e intensidade das alterações nos cortes analisados. Para tanto, foram definidos valores representativos para respostas: leve (1), moderada (2) e severa (3). Após treinamento inicial, apenas um avaliador realizou as leituras, tendo sido as lâminas codificadas, para não haver identificação dos grupos pelo avaliador (cegamento).
Análise estatística. 0s resultados do estudo, de caráter qualitativo, foram submetidos à análise descritiva. Os valores (1, 2 e 3) adotados para estudo das alterações, permitiram a aplicação do teste não-paramétrico de Kruskal-Wallis, adotandose um nível de significância de 5\%.

\section{RESULTADOS}

Houve morte de animais em todos os grupos infectados, antes do tempo total de estudo determinado (quarenta dias). No grupo tratado com betametasona $\left(G_{I}\right)$ morreram 5 animais entre $016^{\circ}$ e $039^{\circ}$ dia de estudo (em média, 6 dias de tratamento com betametasona). No grupo tratado com Arctium lappa $\left(\mathrm{G}_{\mathrm{II}}\right)$, houve apenas uma morte (14 dias de tratamento com extrato) e no grupo infectado, sem tratamento $\left(\mathrm{G}_{\mathrm{III}}\right)$, morreram dois camundongos. Na avaliação visual, macroscópica, o grupo $G_{I}$ apresentou lesões extensas de infarto intestinal e aderências com presença de fibrina, além de broncopneumonia e fígado amarelado. No grupo $G_{\text {III }}$ foram observadas alterações semelhantes àquelas encontradas no $\mathrm{G}_{\mathrm{I}}$, além de áreas brancacentas de infarto em um dos pólos do baço demonstrando infarto esplênico. Os demais grupos não apresentaram lesões macroscópicas importantes.

No estudo histológico, as alterações mais importantes encontradas no $\mathrm{G}_{\mathrm{I}}$ foram infartos nos intestinos delgado e grosso, baço, pâncreas e fígado. Esteatose hepática, neste grupo, atingiu aproximadamente $15 \%$ do tecido analisado. Outras alterações, menos freqüentes, incluíram presença de vermes adultos na aorta, na artéria pulmonar, no coração e nos pulmões. 0 grupo $G_{\text {II }}$ apresentou infarto transmural no intestino delgado, necrose de coagulação, fígado com esteatose micro e macrogoticular chegando a $70 \%$, hepatite reacional e broncopneumonia. 0 grupo $\mathrm{G}_{\mathrm{III}}$ exibiu infartos nos intestinos delgado e grosso, esteatose hepática macrogoticular focal, rins com necrose tubular aguda, baço com focos de infarto e hemorragia pulmonar. 0 grupo $\mathrm{G}_{\mathrm{IV}}$ apresentou os órgãos sadios.

$\mathrm{Na}$ análise de infiltrado eosinofílico, houve diferença significativa para os órgãos: intestino delgado, intestino grosso e fígado, entre tratamentos. Observando a Figura 1, nota-se que os grupos $G_{I}$ e $G_{I V}$ foram diferentes significativamente dos grupos $G_{\text {II }}$ e $G_{\text {III }}(p<0,05)$. Tanto $G_{\text {I }}$ e $G_{\text {IV }}$ quanto $G_{\text {II }}$ e $G_{\text {III }}$ foram semelhantes entre si. Alterações em baço e pulmões não diferiram entre grupos. Apesar de, visualmente diferentes, a análise estatística aplicada aos resultados mostrou que não há diferença, fato dos dois primeiros estarem abaixo da mediana, o que não acontece com os dois últimos.

De forma semelhante aos resultados encontrados no infiltrado eosinofílico, as mesmas diferenças foram encontradas entre os tratamentos, com relação à análise dos granulomas, para os órgãos: intestino delgado e intestino grosso. Não houve diferença entre tratamentos, entretanto, com relação a alterações hepáticas, esplênicas e pulmonares (Figura 2). 


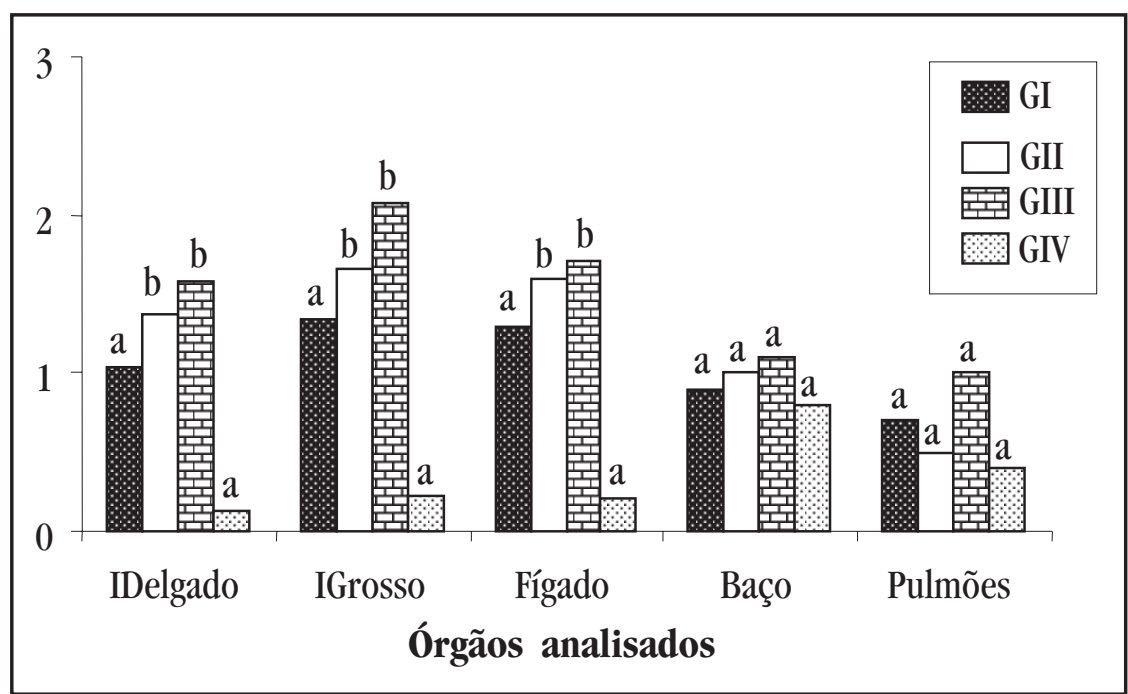

Figura 1 - Intensidade de infiltrado eosinofílico nos diferentes órgãos de camundongos tratados com betametasona $\left(G_{I}\right)$, Arctium lappa $\left(G_{I}\right)$ e controles positivo $\left(G_{I I}\right)$ e negativo $\left(G_{I V}\right)$. Intensidade do infiltrado: 1 (leve); 2 (moderado) e 3 (severo). Tratamentos com letra "a" são semelhantes entre si e diferentes de tratamentos com letra " $b$ ”. Kruskal Wallis $(\mathrm{P}<0,05)$.

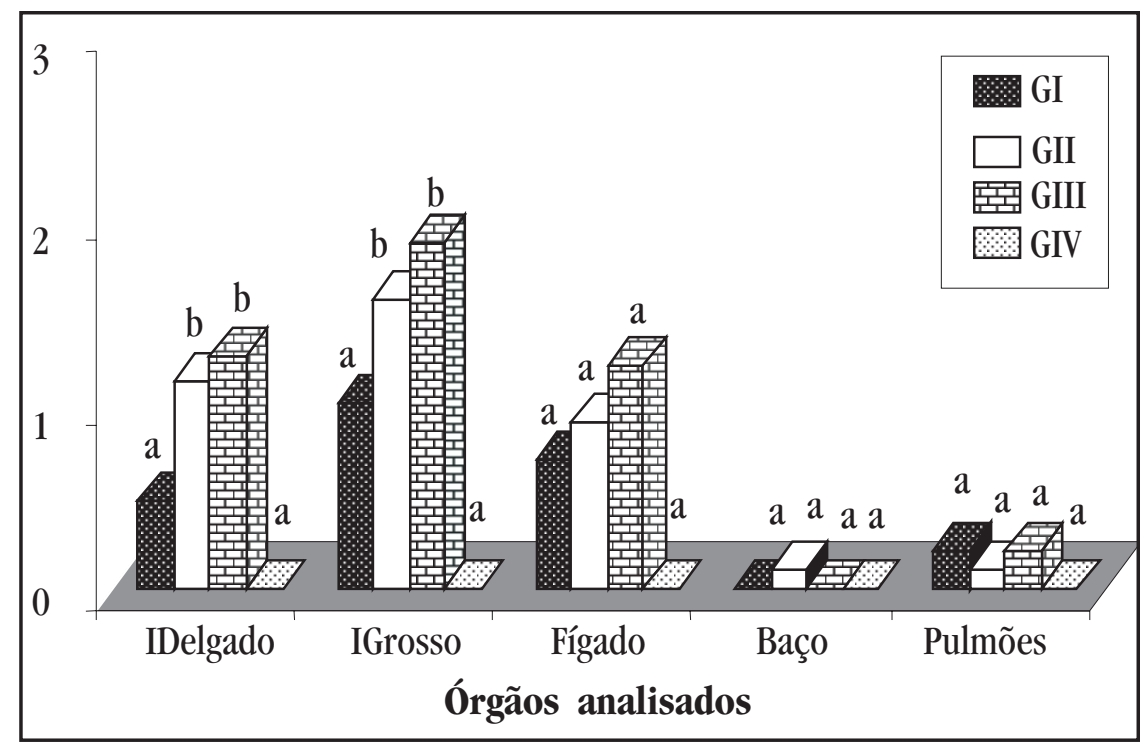

Figura 2 - Intensidade de granuloma nos diferentes órgãos de camundongos tratados com betametasona $\left(G_{I}\right)$, Arctium lappa $\left(G_{I I}\right)$ e controles positivo $\left(G_{I I I}\right)$ e negativo $\left(G_{I V}\right)$. Intensidade do granuloma: 1 (leve); 2 (moderado) e 3 (severo). Tratamentos com letra "a" são semelhantes entre si e diferentes de tratamentos com letra " $b$ ”. Kruskal Wallis $(\mathrm{P}<0,05)$.

\section{DISCUSSÃo}

A angiostrongilíase abdominal é uma doença que produz reações granulomatosas e infiltrados eosinofilicos significativos ${ }^{11}$. Clinicamente, costuma-se prescrever fármacos antiinflamatórios para o tratamento de sinais e sintomas agudos da infecção. Não existe, entretanto, estudos adequados que demonstrem a eficácia do uso de antiinflamatórios na evolução das lesões ${ }^{89}$.

Neste estudo, os tratamentos empregados para o controle da inflamação induzida por Angiostrongylus costaricensis (betametasona e extrato de Arctium lappa) foram diferentes entre si, mas não mostraram eficácia na proteção das lesões. Ao contrário, o tratamento com betametasona mostrou-se lesivo, não evitando a progressão da doença e levando a óbito
$50 \%$ dos animais estudados com relação ao grupo infectado negativo com $20 \%$ de mortes. Para Hwang ${ }^{6}$, o uso de antiinflamatórios esteroidais pode aumentar os níveis de substância $\mathrm{P}$ em intestino, efeito que, acrescido de uma redução da defesa imunológica, pode ter sido responsável pela resposta observada.

Apesar de semelhanças encontradas estatisticamente na comparação entre os animais tratados com betametasona e os animais sem infecção (normais), estes resultados não significam boa resposta do fármaco com relação à infecção pelo parasita. Trata-se na verdade, da detecção de poucos eosinófilos e granulomas nos dois grupos, por causas diferentes, ou seja, a ausência de células eosinofílicas e a formação de granulomas observados com a betametasona podem ser explicados pelo fato de a betametasona diminuir ou prevenir a resposta dos tecidos 
aos processos inflamatórios, com redução dos sintomas da inflamação, sem tratar a causa subjacente. Desse modo, inibe a acumulação de células inflamatórias nas zonas de inflamação, inibindo também a fagocitose, a liberação de enzimas lisossômicas e a síntese ou liberação de vários mediadores químicos da inflamação.

0 tratamento com extrato aquoso de Arctium lappa resultou em um pequeno efeito antiinflamatório que não permitiu melhora significativa ou proteção de lesões, mas, comparativamente ao tratamento com betametasona, evitou 0 desenvolvimento de lesões graves e teve apenas $10 \%$ de óbito. A atividade antiinflamatória da Arctium lappa parece relacionada à remoção de radicais livres conforme estudos realizados em animais de laboratório, em modelos de inflamação aguda induzida por carragenina ${ }^{27}$.

Os resultados observados com os agentes antiinflamatórios usados neste estudo não foram surpreendentes, uma vez que células inflamatórias têm como função defender o tecido lesado e promover sua regeneração. Com a redução da inflamação, o tecido fica susceptível ao ataque dos agentes agressivos, neste caso, o Angiostrongylus costaricensis e, com isso, ocorre facilmente à morte celular ou necrose.

Questiona-se desta forma, o emprego clínico de antiinflamatórios no controle dos sintomas da angiostrongilíase abdominal, uma vez que podem comprometer a capacidade orgânica de proteção contra a progressão das lesões induzidas pelo Angiostrongylus costaricensis. Efeito semelhante a este, pode ser observado no tratamento de colite ulcerativa e doença de Crohn com corticosteróides, o qual não modifica a evolução da doença e pode mascarar sinais e sintomas de complicações, tais como perfuração e peritonite ${ }^{13}$.

\section{REFERÊNCIAS}

1. Cespedes R, Salas J, Mekbel S, Troper L, Mullner F, Morera P. Granulomas entéricos y linfáticos com intensa eosinofilia tisular producidos por um estrongilídeo (Strongylata). Acta Médica Costarricense 10: 235-255, 1967.

2. Der DP, Coll CN, Hsiang JT. Activity of burdock (Arctium lappa Linne): Its scavenging effect on free-radical and active oxygen. Journal American Oil Chemists Society 75: 455-461, 1998.

3. Graeff-Teixeira C, Agostini A, Rodriguez R. Angiostrongilíases. In: Coura JR (ed) Dinâmica das Doenças Infecciosas e Parasitárias, $1^{a}$ edição, Editora Guanabara Koogan, Rio de Janeiro p. 1077-1079, 2005.

4. Graeff-Teixeira C, Coura L, Lenzi H. Abdominal Angiostrongyliasis - an under diagnosed disease. Memórias do Instituto Oswaldo Cruz 82: 353-354, 1987.

5. Grases F, Melero G, Costa-Bauza A, Prieto R, March JG. Urolithiasis and Phytotherapy. International Urology and Nephrology 26: 507-511, 1994.

6. Hwang L, Leichter R, Okamoto A, Payan D, Collins SM, Bunnett NW. Downregulation of neutral endopeptidase in the inflamed rat intestine. American Physiological Society 264: 735-743, 1993.

7. Lin CC, Lin JM, Yang JJ. Anti-inflamatory and radical scavenger: Effects os Arctium lappa. The American Journal of Chinese Medicine 24: 127-137, 1996.

8. Morera P, Bontempo I. Accion de algunos anthihelminticos sobre Angiostrongylus costaricensis. Revista Médica del Hospital Nacional de Ninõs 20: 165-174, 1986.

9. Moreira P, Perez F, Mora F, Castro L. Visceral larva migrans-like syndrome caused by Angiostrongylus costaricensis. The American Journal of Tropical Medicine and Hygiene 31: 67-70, 1982.

10. Pena MP, Andrade Filho J, Assis SC. Angiostrongylus costaricensis: First record of its occurrence in the state of Espírito Santo, Brazil, and a revieco of its geographic distribution. Revista do Instituto de Medicina Tropical de São Paulo 37: 369-374, 1995.

11. Robles G, Loria R, Lobo F. Granuloma Eosinófilo Parasitário Intestinal. Revista Médica del Hospital Nacional de Ninõs 3: 67-80, 1968.

12. Sanahuja F, Cortês R, Gonzalez G. Angiostrongilosis Abdominal. Aspectos clínicos, tratamiento y revisión de la literatura. Boletin Médico del Hospital Infantil de Mexico 44: 4-9, 1987.

13. Wannmacher L, Ferreira MB. Princípios gerais no tratamento da inflamação. In: Fuchs F, Wannmacher L, Ferreira MB. Farmacologia Clínica, Fundamentos da Terapêutica Racional, 3- edição, Editora Guanabara Koogan, Rio de Janeiro, p. 294-295, 2004. 